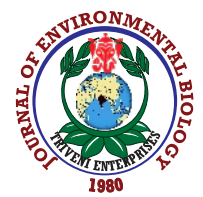

\title{
A sustainable castor oil-based agro formulation with cartap hydrochloride for potential control of pathogenic Xanthomonas oryzae in Oryza sativa L.
}

\author{
M. Ramadass and P. Thiagarajan* \\ School of Biosciences and Technology, Vellore Institute of Technology, Vellore-632014, India \\ *Corresponding Author Email : padmadk4@gmail.com
}

Received: 11.02.2020

Revised: 23.05 .2020

Accepted: 07.08 .2020

\begin{abstract}
Aim: The aim of the present study was to synthesize a castor oil-based matrix (COBM) for preparing a castor oil-based agro-formulation with cartap hydrochloride for controlling Xanthomonas oryzae, a rice pathogen.

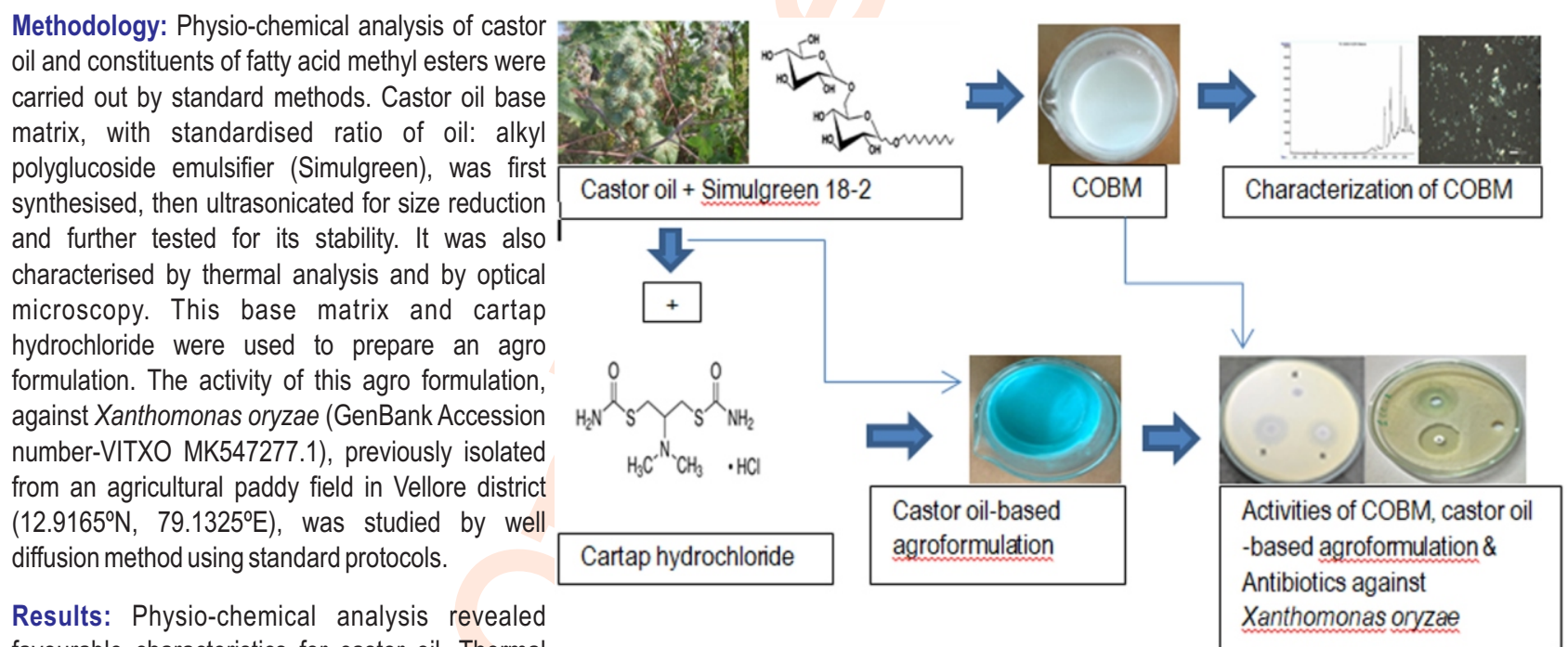

favourable characteristics for castor oil. Thermal

analysis and optical polarised microscopic studies showed the presence of liquid crystals in the formulated base matrix. Its agro-formulation with cartap hydrochloride showed $22 \mathrm{~mm}$ zone of inhibition against the isolated Xanthomonas oryzae. However, aqueous solution of cartap hydrochloride showed a $13 \mathrm{~mm}$ zone of inhibition only, when tested at a similar concentration (2000 ppm), by well diffusion studies.
\end{abstract}

Interpretation: The liquid crystal containing base matrix facilitated slow and sustained release of cartap hydrochloride from the castor oil-based agroformulation to achieve good activity against Xanthomonas oryzae.

Key words: Agro formulation, Cartap hydrochloride, Castor oil, Oryza sativa, Simulgreen, Xanthomonas oryzae

How to cite : Ramadass, M. and P. Thiagarajan: A sustainable castor oil -based agro formulation with cartap hydrochloride for potential control of pathogenic Xanthomonas oryzae in Oryza sativa L. J. Environ. Biol., 42, 74-81 (2021). 


\section{Introduction}

Ricinus communis L. (castor plant) is a traditional agricultural crop widely cultivated in Western India, China and Brazil. It grows well in dry subtropical regions and wet tropics between $20-25^{\circ} \mathrm{C}$. Castor oil, a commercially valuable product, is extracted from oil-rich seeds of the plant (Nangbes et al., 2013). The oil has been traditionally useful in cosmetic, food, medicinal, pharmaceutical, lubricant, detergent and other chemical industries, for manufacturing high-value products (Ogunniyi, 2006; Mutlu and Meier, 2010). However, it accounts for only $0.15 \%$ of the global production of vegetable oils. Its processing procedures have now been optimized to cater to its commercial demand as many promising applications for this oil have been researched and reported (Patel et al., 2016).

Rice (Oryza sativa) is a widely consumed staple food in Asian countries. It is highly susceptible to bacterial pathogens, viz., Xanthomonas oryzae pv. oryzae and Xanthomonas oryzae pv. oryzicola, which causes blight and leaf streaks in plants (Zhang and Wang, 2013). Development of genetically resistant plant varieties, as well as chemical/biological treatment strategies (Evidente et al., 2011), are used for imparting resistance to plants against pests attack. Modern agrarian practices focus on agro formulations, that combine mutually compatible and pestspecific insecticides, herbicides and antimicrobial compounds that blend with plant growth regulators in aqueous or petrochemical solvent bases, for rendering holistic crop protection (Jiang et al., 2011; Saini et al., 2015).

Although such treatments are reasonably successful (Dawson et al., 2010), the toxicity of these constituents, towards untargeted organisms, across all biological trophic levels over prolonged periods raises concern (Stone, 2014). Continuous exposure to high concentrations of any chemical-based agro formulations causes immediate and long-term detrimental effects on human health and environment (Boorugu and Chrispal, 2012; Erkmen et al., 2013, Mostafalou and Abdollahi, 2017). These also include reproductive toxicity in male Wistar rats (Sharma et al., 2013), aquatic toxicity (Cruz et al., 2014), and toxicity in wild animals like sloths (Branford et al., 2014). Declining availability of fossil fuels, which serve as base matrices in such formulations, is also an issue that needs to be taken into account.

In this context, vegetable oils, preferably emulsified with biocompatible emulsifiers, can be employed as useful base matrices for pesticide delivery. These oils can effectively and economically displace mineral oils, and organic solvents from agro-formulations (Pratap and Bhowmick 2008; Sanchez et al., 2011). They are also environment-friendly and form a part of renewable resources. It is also possible to source them from waste products that are discarded by related industries by using simple treatment procedures. They can be loaded with hydrophilic and lipophilic pesticides, either singly or in combinations. Within the limits of thermodynamic requirements, their constituents' concentrations and ratios can be fine-tuned during synthesis to achieve the required rheology for delivery. It is also possible to modify their particle sizes and control their zeta potentials. Tuning their other structural and stability characteristics is also feasible by adopting a combination of soft and aggressive methodologies. Such procedures can include crash dilution, phase inversion, ultrasonication and high-pressure homogenization that can be selected appropriately during their synthesis (Perazzo et al., 2015; Trujillo-Cayado et al., 2015). In the present study, a novel castor oil-base matrix (COBM), with Simulgreen 18-2, a long chain mixed alkyl polyglucoside (APG) emulsifier, was formulated and characterized. Simulgreen is known to excellently emulsify this oil to produce oil in water formulation that incorporates liquid crystals with depot water. An agro-formulation, prepared by loading cartap hydrochloride onto this base (castor oil-based agro formulation) was then tested for its potential ability to control pathogenic Xanthomonas oryzae pv. oryzae that was previously isolated from infected leaves of rice plant.

\section{Materials and Methods}

Physio-chemical characterisation and GC-MS analysis of castor oil: Physio-chemical parameters of castor oil, procured from Falcon Essential Oils, Bengaluru, were analysed by standard methods as prescribed by the American Oil Chemists Society. Its FAME analysis was carried out by GC-MS (Agilent GC 7890A MS5975C with Agilent DB5MS capillary column, $30 \mathrm{~m}$, $0.25 \mathrm{~mm}$ internal diameter, $0.25 \mu \mathrm{m}$ film thickness) and the constituents were identified using NIST Library.

Synthesis and characterisation of COBM: Five gram of castor oil was warmed to $80^{\circ} \mathrm{C}$ in 10 volumetric flasks. Then, 0.5 to five grams of Simulgreen (Yasham Speciality Chemicals Limited, Mumbai), in increments of $0.5 \mathrm{~g}$ (oil: Simulgreen ratio 1:0.1 to 1:1), were slowly dissolved in the oil contained in each of the ten flasks. Milli $Q$ water, warmed to $80^{\circ} \mathrm{C}$, was added drop-wise, with constant stirring, to make up the volume to $50 \mathrm{ml}$ in all flasks. After $24 \mathrm{hr}$, formulations with no phase separation, cracking or creaming were selected and ultrasonicated for 5 min (Sonics Vibra cell, $20 \mathrm{kHz}$ frequency, $13 \mathrm{~mm}$ probe diameter, $50 \%$ intensity, $300 \mathrm{~W} / \mathrm{cm}^{2}$ amplitude, pulse rate of 2 per minute). For droplet size analysis, $20 \mu \mathrm{g}$ of each formulation was diluted with $100 \mathrm{ml}$ of water and filtered through a $0.4 \mu \mathrm{m}$ syringe filter (Horiba Scientific SZ 100 with Windows Z7 type version 2.00 software of Microsoft Corporation, Redmond, WA, USA, scattering angle $90^{\circ}$ at $25^{\circ} \mathrm{C}$ ). One way ANOVA and Tukey's test were carried out to identify the formulation that had least particle size. This formulation was labelled as Castor Oil Base Matrix (COBM).

Zeta potential and electrophoretic mobility were measured (Horiba Scientific SZ 100) for COBM. The $\mathrm{pH}$ was recorded by direct immersion of $\mathrm{pH}$ probe into COBM after $0.1 \mathrm{w} / \mathrm{v}$ dilution (pH meter HI 8417, Hanna Instruments, Woonsocket, USA). Conductivity (CDM230, Copenhagen, Denmark) and turbidity (Systronics Digital Nephelo Turbidity Meter 132) were estimated made after similar dilutions. Viscosity of COBM was 
measured after dilution (16 $\mathrm{gl}^{-1}$, after multiple trials) with a laboratory glass viscometer. FTIR spectroscopic analysis (ALPHA II, Bruker, Optics, Germany) between $4000-500 \mathrm{~cm}^{-1}$ was carried out using ATR technique. For thermo-gravimetric analysis (TGA) (TGA, Perkin Elmer Model Pyris1), 13-14 mg of COBM, was gradually heated in an aluminium pan $\left(30^{\circ}\right.$ to $110^{\circ}$ at $5^{\circ} \mathrm{C}$ per minute), and weight loss, as a function of temperature, was recorded and plotted. For differential scanning calorimetry (DSC, Perkin Elmer (Pyris Diamond), approximately $10 \mathrm{mg}$ of COBM was taken in an aluminium pan, tightly sealed and gradually heated $\left(30^{\circ}\right.$ to $110^{\circ} \mathrm{C}$ at $1^{\circ} \mathrm{C}$ per minute) with an empty pan as reference. Heat flow, as a function of temperature, was recorded and plotted.

The results of the experiments in triplicate were expressed as mean \pm SEM. A blob of COBM was placed on a glass coverslip and smeared into a thin film for polarized optical microscopic analysis (POM, Olympus BX-51 combined with UIS2 objective lens at $50 \mathrm{X}$, with cross polarizers and a wavelength plate at $\left.25 \pm 2^{\circ} \mathrm{C}\right)$. An infrared light heating device heated $\mathrm{COBM}\left(1^{\circ} \mathrm{C}\right.$ per minute) upto $100^{\circ} \mathrm{C}$, and then for every $5^{\circ} \mathrm{C}$ increase in temperature, the images were captured. For studies on shelf-life stability, COBM was maintained at $37^{\circ} \mathrm{C}$ for 180 days, and it was visually observed every week for any signs of de-stabilization. COBM was also centrifuged (REMI Microprocessor Research Centrifuge PR-24) for 30 min at 5000 rpm and observed for any signs of destabilisation.

Synthesis of castor oil-based agro formulation with cartap hydrochloride and its activity against pathogenic Xanthomonas oryzae: Three grams of cartap hydrochloride was dispersed in $42.5 \mathrm{ml}$ of Milli $\mathrm{Q}$ water, ultrasonicated for $15 \mathrm{~min}$, and warmed to $80^{\circ} \mathrm{C}$. Five gram of castor oil was warmed to $80^{\circ} \mathrm{C}$ in a volumetric flask, and $2.5 \mathrm{gm}$ of Simulgreen was slowly dissolved in it. Cartap hydrochloride solution, maintained at $80^{\circ} \mathrm{C}$, was then added drop-wise to make up the total volume to $50 \mathrm{ml}$. Twenty four hours later, it was ultrasonicated for 5 min under similar conditions that were adopted for COBM. Particle size, zeta potential, electrophoretic mobility, $\mathrm{pH}$, conductivity and turbidity, viscosity $\left(33 \mathrm{gl}^{-1}\right)$, and stability studies were also carried out for this castor oil-based agro formulation. An infected leaf of Oryza sativa was collected from paddy field in the Vellore district. Xanthomonas $s p$. was isolated by standard methods, and its pathogenicity was established through exopolysaccharide production. It was then confirmed by $16 \mathrm{~S}$ rRNA sequencing as Xanthomonas sp. (unpublished results) before submission to Gen-Bank (Accession number- VITXO MK547277.1). The activities of a group of broad-spectrum antibiotics, commercial cartap hydrochloride solution, COBM, and castor oil-based agro formulation, were assessed against the bacteria, by following the CLSI guidelines.

\section{Results and Discussion}

Castor oil is a non-edible, renewable, inexpensive, and environmentally benign product. Different varieties of castor seeds contain $45-55 \%$ of oil by weight. Generally, allergens like ricin, ricinine, ricinoleic acid and $2 S$ albumin are not extracted in the oil during processing, making it safe for use (Johnson, 2007). Simulgreen 18-2 is an alkyl polyglucoside emulsifier, with hydroxystearyl alcohol and glucoside groups (Roso et al., 2012). It belongs to a class of non-ionic, biodegradable, biocompatible, and nontoxic emulsifiers, free from solvents and preservatives. It is produced from natural sources and contain liquid crystal reservoirs to improve hydration, and to form elastic networks with water. Due to its moistening property and lack of soaping effect, it prevents water loss in the applied systems and ensures a better flow of their constituents (Sulek et al., 2013). It is also important to state here that pesticide formulations invariably contain ionic and non-ionic adjuvants, like different ethoxylates, that are technically mixtures of several compounds in different ratios. Currently, their toxic impact on the ecosystem has raised concerns, as they increase the mobility of various pollutants in the soil (Krogh et al., 2003). However, Simulgreen is as a non-ethoxylated adjuvant, with a favourable ecological profile that is safe for use in agro-formulations.

The odourless pale yellow coloured castor oil contains no sediment and has a molecular weight 298.46 , relative density 0.9222 , and viscosity 68.04 cst, which is higher than other vegetable oils. A moisture content of $0.14 \%$ reflects a good shelf life. An acid value of $1.82 \mathrm{mg} / \mathrm{g}$ attests to the excellent quality of seeds used for extraction. High unsaturated acid content of castor oil reflect iodine value of $86.5 \mathrm{mg} / \mathrm{g}$. The saponification value of $180.22 \mathrm{mg} / \mathrm{g}$ is due to high molecular weight and fatty acid glyceride constituents. It has high phosphorus content $(3.88 \mathrm{mg}$ $\mathrm{kg}^{-1}$ ), and hence, can serve as an organic fertilizer and source of organic manure for crops like rice, wheat, tomato, sugarcane etc. Its refractive index is $1.479\left(25^{\circ} \mathrm{C}\right)$, and it contains $3.56 \%$ of unsaponifiable matter. Salimon et al. (2010) had also reported an iodine value of $84.5 \mathrm{mg} \mathrm{g}^{-1}$, saponification value of $183 \mathrm{mg} \mathrm{g}^{-1}$, refractive index of $1.47\left(25^{\circ} \mathrm{C}\right)$ and unsaponifiable matter of $3.40 \%$ for Malaysian castor seed oil.

GC-MS analysis of castor oil showed no peaks for rincin derivatives attesting its safety for use. Carvacrol, butanoic acid, and leucine were the major compounds identified. Linoleic acid, vitamin $E$, squalene, propionic acid, and a benzoquinone derivative, were observed with peak areas of $<10 \%$, along with other minor compounds (peak areas of $<1.0 \%$ ). Many of these compounds show excellent antimicrobial, anti-inflammatory, and antioxidant properties. Carvacrol, in particular, is a monoterpenoid phenol with low toxicity and is known to prevent bacterial contamination and proliferation by damaging cell membranes. Emulsion based agro-formulations with different oils, loaded with variety of chemical and biopesticides, have been reported for controlling pests in agricultural crops (Diaz-Blancas et al., 2016). Oil in water emulsion formulated in this study by a phase inversion technique consisted of fine oil droplets dispersed in the continuous phase. Such formulations score best in terms of lowered particle size, excellent long-term stability, and favorable rheological properties (Kumar et al., 2015). Further, emulsions prepared by initially adding the emulsifier to oil phase are more stable than those formulated vice versa (Feng et al., 2018). 


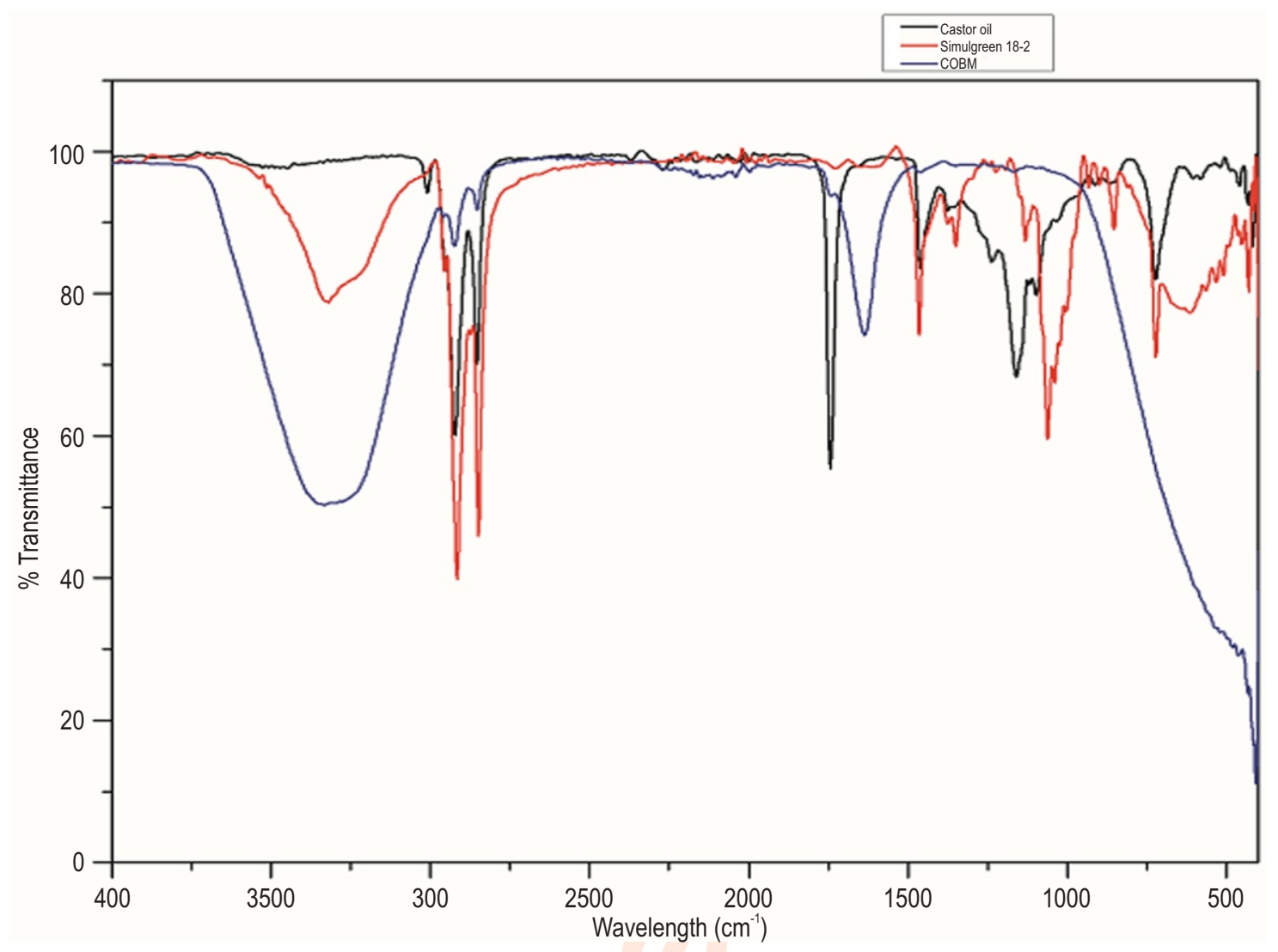

Fig. 1: FTIR spectra of castor oil, Simulgreen18-2 and COBM.

The formulation with oil: emulsifier ratio of 1:0.5 (5 g oil, $2.5 \mathrm{~g}$ emulsifier made up to $50 \mathrm{ml}$ with Milli $Q$ water) was visually stable and showed well-dispersed oil globules. After ultrasonication, its particle size was $109 \mathrm{~nm}$. An equally stable 1:0.6 ratio formulation had a particle size of $128 \mathrm{~nm}$. Ultrasonication is method to reduce particle sizes in systems as compared to conventional high-shear methods and is beneficial in emulsion technology (Sivakumar et al., 2014). As the particle size of both these formulations did not show a statistically significant difference $(p<0.001)$, the formulation with an oil: emulsifier of 1:0.5, was labelled as COBM and used for further studies as it was more economical.

It is important to note here that on spraying, COBM provides additional moisture to plant parts. The oil component also creates a barrier guard to pests, thus rendering excellent physical protection. Beneficial properties concerning slow and sustained delivery of actives, inherent in emulsions, apply to COBM too. Slow and sustained release of pesticides will make them available for acting against pests over a long duration. Therefore, dose dumping of agro-formulations can be avoided, thereby reducing toxicity effects and adverse environmental impacts. For COBM with particle size of $109 \mathrm{~nm}$, the zeta potential was $-66.0 \mathrm{mV}$. Zeta potential determines the system's stability, and a mean value above 30 or below -30 is favourable (Wiacek and Chibowski, 1999), as observed for COBM in this study. The electrophoretic mobility of COBM was $-3.46 \mu \mathrm{mcm} / \mathrm{Vs}$. Its $\mathrm{pH}$ was neutral, which is well suited for the synthesis of agro-formulation. Conductivity and turbidity values were $90.3 \mathrm{~S} / \mathrm{m}$ and $96 \mathrm{FNU}$, respectively. The former parameter shows a substantial amount of bulk water present in this system, as known for this emulsifier (Savic et al., 2011). Small droplet size increases the intensity of light scattering, thus reducing turbidity, and enhancing stability. Viscosities of commercial pesticides used for spraying, range between 1.1-1.3 mPa.S (Carvalho et al., 2018).

Hence, COBM was diluted (after multiple trials), to $16 \mathrm{gml}^{-1}$, to obtain a viscosity of $1.10 \mathrm{mPa}$.S. Specific functional groups in castor oil constituents were detected using FTIR spectroscopy (Fig. 1). C-H (2922.16 cm $\left.\mathrm{cm}^{-1}\right), \mathrm{C}=\mathrm{O}\left(2852.72 \mathrm{~cm}^{-1}\right)$, and $\mathrm{C}=\mathrm{C}$ $\left(1462.04 \mathrm{~cm}^{-1}\right)$ bonds appeared as bands at their characteristic wavenumbers. A broad peak (strong intensity) at $3008.95 \mathrm{~cm}^{-1}$ was mainly contributed by-OH of carvacrol and p-hydroxy amphetamine. Additionally, an alcoholic C-O bond in these compounds showed as a sharp peak at $1097.31 \mathrm{~cm}^{-1}$. $\mathrm{COOH}$ peak $\left(2922.16 \mathrm{~cm}^{-1}\right)$ was due to propanoic acid, leucine, and hydrocinnamic acid. Similar results have been reported for castor oil (Bhosale et al., 2015). In the case of Simulgreen, strong peak 

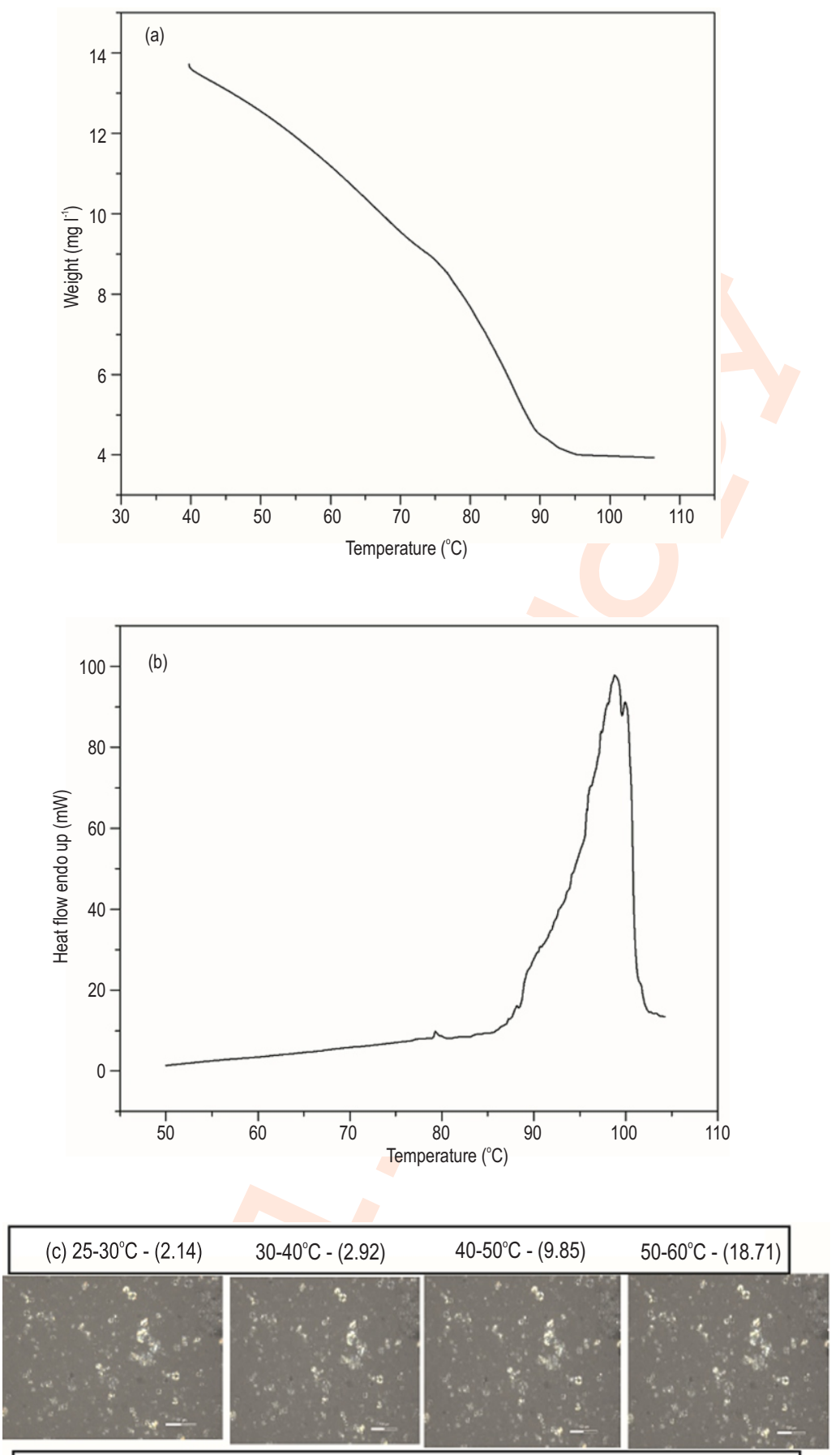

\begin{tabular}{|c|c|c|c|}
\hline $60-70^{\circ} \mathrm{C}-(31.42)$ & $70-80^{\circ} \mathrm{C}-(44.28)$ & $80-90^{\circ} \mathrm{C}-(67.14)$ & $90-100^{\circ} \mathrm{C}-(71.42)$ \\
\hline
\end{tabular}
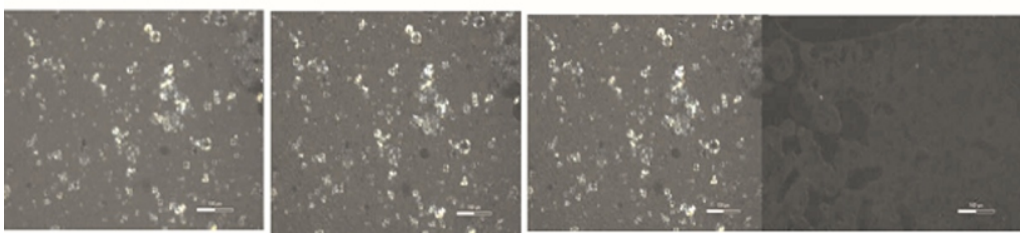

Fig. 2: Thermal and microscopic analysis of COBM; (a)Thermo gravimetric analysis of COBM; (b) Differential scanning calorimetric analysis of COBM and (c) POM images of COBM from $25-100^{\circ} \mathrm{C}$ showing liquid crystals till $90^{\circ} \mathrm{C}(\%$ water loss for specific range of temperatures is given in brackets). 


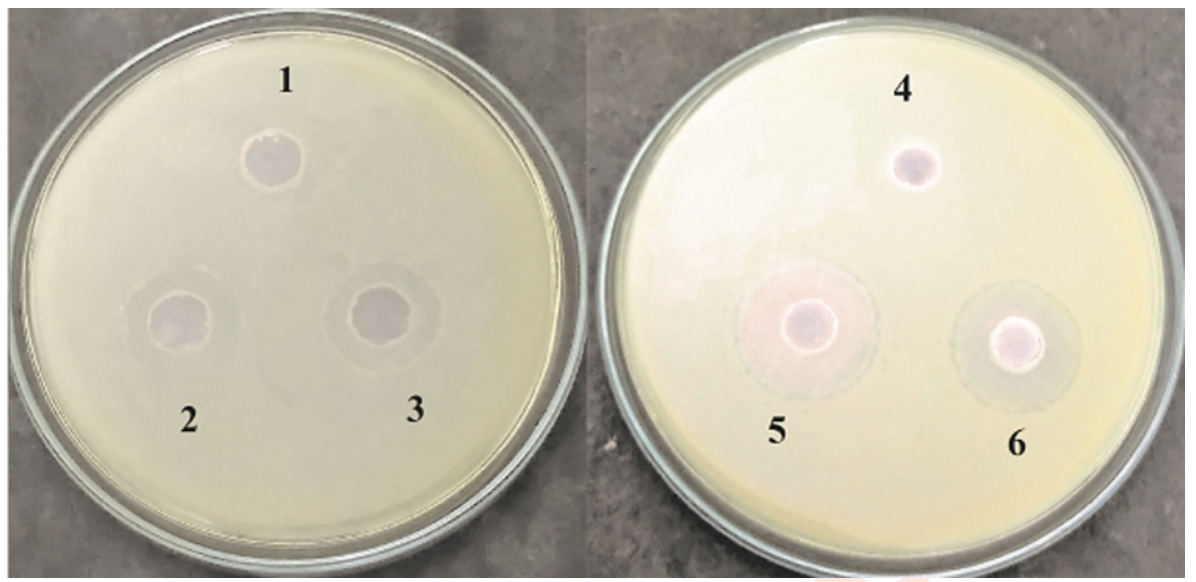

Fig. 3: Anti-bacterial activities against isolated Xanthomonas oryzae. (1) Water; (2) Aqueous cartap hydrochloride solution (2000 ppm); (3) Aqueous agrimycin solution (100 ppm); (4) Diluted sprayable COBM; (5) Diluted sprayable castor oil-based agro-formulation with cartap hydrochloride (2000 ppm) and (6) Diluted sprayable castor oil-based agro formulation with agrimycin (100 ppm).

at $3319.49 \mathrm{~cm}^{-1}$ was due to $0-\mathrm{H}$ group. A broad peak at $3300 \mathrm{~cm}^{-1}$, observed in COBM, indicates extensive hydrogen bonding in the system due to large quantity of water. Thermal studies distinguish between surface/bulk water, and the depot water present in liquid crystals. Thermal stabilities of castor oil, and their methyl esters, have been reported (Gallego-Gomez et al., 2016). COBM, when heated from $30^{\circ}$ to $110^{\circ} \mathrm{C}$ (TGA studies) showed a gradual, cumulative weight loss from $2 \%$ to around $71 \%$ (Fig. 2a). Weight loss of $67 \%$ observed till $90^{\circ} \mathrm{C}$, was due to loss of bulk/surface water. Conductivity values $(90.3 \mathrm{~S} / \mathrm{m})$ also attest the presence of such water. DSC studies with COBM revealed a single sharp endothermic peak at $100^{\circ} \mathrm{C}$ (Fig. 2b) that shows transition from mesomorphic liquid crystalline phase to liquid phase.

The images captured by OPM during heating cycle also confirm these results. Liquid crystals in COBM that ensconce depot water were almost retained and remained undamaged till $90^{\circ} \mathrm{C}$, after which these crystals brokedown (Fig. 2C). A tung-oil based emulsion also shows similar results (Salimon et al., 2010). After low-speed centrifugation, there were no sign of visual destabilization (creaming, cracking, oil droplet formation, or phase separation) in COBM. COBM was also stable at $37^{\circ} \mathrm{C}$ for 180 days. Such results are indicators of stable emulsion formulations. Cartap is a thiocarbamate insecticide (C7H16CIN3O2S3) with chemical composition S-[3-carbamoyl sulfanyl-2(dimethylamino) propyl] carbamothioate hydrochloride. It has low toxicity and commonly used to control rice stem borer and leaf folder infections in crops like rice and sugarcane. It effectively controls chewing and sucking pests. It is a nereistoxin analog when ingested, paralyses the insects. It causes skin and ocular irritation in humans upon direct exposure (Boorugu and Chrispal, 2012). Hence in the present study, cartap is loaded into COBM to minimize its direct contact with humans, plants, and the environment in general, during spraying process. Such loading onto a base matrix will reduce the effect of unwarranted toxicity at all levels and facilitate its slow release for pathogenic control. The particle size, zeta potential and electrophoretic mobility of castor oil-based agro formulation were $108 \mathrm{~nm},-67.0 \mathrm{mV}$ and -3.41 $\mu \mathrm{mcm} / \mathrm{Vs}$, respectively. Addition of cartap hydrochloride to COBM makes it more acidic, therefore its $\mathrm{pH}$ was 6.2. Acidic conditions are well suited for the stability of cartap hydrochloride solutions (Hartley and Kidd, 1987). This in turn, enhances its activity for suitable applications. The conductivity and turbidity level of this agro formulation was $90 \mathrm{~S} / \mathrm{m}$ and 73FNU, respectively. As with $\mathrm{COBM}$, the viscosity of this agro formulation (33.3 $\mathrm{g} \mathrm{l}^{-1}$ dilution after multiple trials), optimized for spraying, was $1.10 \mathrm{mPa}$.S. The final concentration of cartap hydrochloride in this diluted solution was $2000 \mathrm{ppm}$.

Antibiotics are known to effectively control Xanthomonas axonopodis pv. citri (Mubeen et al., 2015). In the present study, several antibiotics, which include ciprofloxacin, penicillin, tetracycline and erythromycin among others, inhibited the growth of isolated Xanthomonas oryzae. Ciprofloxacin (CIP10) showed the highest zone of inhibition $(37 \mathrm{~mm})$ while COBM showed a zone of $10 \mathrm{~mm}$. However, it is interesting to note that, although a simple 2000 ppm aqueous solution of cartap hydrochloride produced a zone of only $13 \pm 0.2 \mathrm{~mm}$, the diluted sprayable castor oil-based agro-formulation, loaded with 2000 ppm of cartap hydrochloride, showed a statistically significant higher zone of inhibition at $22 \mathrm{~mm}$ (Fig.3). Loading cartap hydrochloride in COBM increases the bacterial inhibition zone by almost $69 \%$. Even though plain COBM shows a zone of inhibition of only 10 $\mathrm{mm}$ against $X$ anthomonas oryzae, it serves as an excellent base matrix for loading cartap hydrochloride to facilitate the latter's slow release to control the pathogen, over a time of $24 \mathrm{hr}$. This release mechanism is more effective than that observed with aqueous pesticide solutions wherein their instantaneous short- 
term action warrants repeated spraying. Such dose dumping causes bioaccumulation of pesticides and harmful environmental consequences. It also results in increased toxicity towards untargeted organisms. The effectiveness of COBM was further confirmed by carrying out similar studies with $100 \mathrm{ppm}$ of agrimycin (also sprayed in paddy fields for controlling Xanthomonas oryzae) instead of cartap hydrochloride, for comparative purposes. Here, a $100 \mathrm{ppm}$ aqueous solution of this antibiotic produced a zone of $16 \mathrm{~mm}$. Its agro formulation (viscosity $1.10 \mathrm{mPa}$.S) with COBM, at same concentration (100 ppm), led to a $44 \%$ higher zone of inhibition (23 mm) (Fig. 3). Another interesting observation is that although aqueous solutions of cartap hydrochloride and agrimycin showed different levels of inhibition with respect to Xanthomonas oryzae $(13 \mathrm{~mm}$ and $16 \mathrm{~mm}$ ), their agro formulations with COBM leads to comparable zones of inhibition $(22 \mathrm{~mm}$ and $23 \mathrm{~mm}$ ). These results emphasize the role of COBM and also importantly, that of liquid crystals containing depot water, in modulating the release of these actives,to achieve maximum control of bacterial plant pathogens. Castor oil-based agro formulation with cartap hydrochloride shows good antibacterial activity against pathogenic Xanthomonas oryzae that causes severe leaf blight disease in rice plants. This sustainable and ecologically benign agro formulationcan serve as an excellent alternative for mineral oil and organic solvent based pesticide formulations.

\section{Acknowledgments}

The authors acknowledge VIT, Vellore, India for providing the seed fund for this study. We thank Dr. N. Thiagarajan, Senior Principal Scientist, CSIR-NAL, Bengaluru for technical inputs, and Mr. N.T. Manikandanath, Technical Officer, CSIR-NAL, Bengaluru, for thermal analyses. We are grateful to Indian Institute of Science (SATF), Bengaluru for providing the polarised optical microscopic test facility.

\section{Add-on Information}

Authors' contribution: P. Thiagarajan: Deciding scope, Design of work plan and methods, verification of results, Final approval of manuscript; M. Ramadass: Carrying out experiments, consolidation of results, preparation of draft manuscript.

Research content: The research contents is original and has not been published elsewhere

Ethical approval: NotApplicable.

Conflict of interest: The author declares that there is no conflict of interest.

\section{Data from other sources: NotApplicable}

Consent to publish: All authors agree to publish the paper in Journal of Environmental Biology.

\section{References}

Bhosale, N., A. Shaik and S.K. Mandal: Synthesis and characterization of castor oil based hybrid polymers and their polyurethaneurea/silica coatings. RSCAdv., 5, 103625-103635(2015).

Boorugu, H.K. and A. Chrispal: Cartap hydrochloride poisoning: A clinical experience. Indian J. Crit. Care Med., 16, 58-59 (2012).

Branford, M.V.P., E. de la Cruz, K. Solano and O. Ramirez: Pesticide exposure on sloths (Bradypus variegatus and Choloepus hoffmanni) in an agricultural landscape of Northeastern Costa Rica. J. Environ. Biol., 35, 29-34 (2014).

Carvalho, F., U. Antuniassi, R. Chechetto and A. Mota: Viscosity, surface tension and droplet size of spray liquids containing formulations of insecticides and fungicides with oil-based adjuvants. Int. Adv. Pestici. Appl. AspectAppl. Biol., 137,183-190 (2018).

Cruz, de la E., V. Bravo-Duran, F. Ramirez and L.E. Castillo: Environmental hazards associated with pesticide import into Costa Rica, 1977-2009. J. Environ. Biol., 35, 43-55 (2014).

Dawson, A.H., M. Eddleston, L. Senarathna, F. Mohamed, I. Gawarammana, S.J. Bowe and N.A. Buckley: Acute human lethal toxicity of agricultural pesticides: A prospective cohort study. PLOS Med., 7, 1-10 (2010).

Diaz-Blancas, V., D.I. Medina, E. Padilla-Ortega, R. Bortolini-Zavala, M. Olvera-Romero and G. Luna-Barcenas: Nanoemulsion formulations of fungicide tebuconazole for agricultural applications. Molecules, 21, 1-12 (2016).

Erkmen, B., S.V. Yerli, F. Erk aken and D. Kolankaya: Persistent organochlorine pesticide residues in water and sediment samples from Lake Manyas, Turkey. J. Environ. Biol., 34, 171-176 (2013).

Evidente, A., V. Venturi, M. Masi, G. Degrassi, A. Cimmino, L. Maddau and A. Andolfi: In-vitro antibacterial activity of sphaeropsidins and chemical derivatives toward Xanthomonas oryzae pv. oryzae, the causal agent of rice bacterial blight. J. Nat. Prod., 74, 2520-2525 (2011).

Feng,J., Q. Chen, X. Wu, S.M. Jafari and D.J. McClements: Formulation of oil-in-water emulsions for pesticide applications: Impact of surfactant type and concentration on physical stability. Environ. Sci. Pollut. Res., 25,1-10 (2018).

Gallego-Gomez, F., V. Morales-Florez, M. Morales, A. Blanco and C. Lopez: Colloidal crystals and water: Perspectives on liquid-solid nanoscale phenomena in wet particulate media. Adv. Colloid Interface Sci., 234,142-160 (2016).

Hartley, D. and H. Kidd: The Agrochemicals Handbook. $2^{\text {nd }}$ Edn., RSC., Lechworth, Herts, UK (1987).

Jiang, L.C., M. Basri, O. Dzolkhifli, M.B.A. Rahman, B.A. Salleh, R.N.J.R.A. Rahman and A. Selamat: Green nano-emulsion intervention for water-soluble glyphosate isopropylamine (IPA) formulations in controlling Eleusine indica (E. indica). Pest. Biochem. Physiol., 102, 19-29 (2011).

Johnson, J.W.: Final report on the safety assessment of Ricinus communis (Castor) seed oil, hydrogenated castor oil, glyceryl ricinoleate, glyceryl ricinoleate, ricinoleic acid, potassium ricinoleate, sodium ricinoleate, zinc ricinoleate, cetyl ricinoleate, ethyl ricinoleate, glycol ricinoleate, isopropyl ricinoleate, methyl ricinoleate, and octyldodecyl ricinoleate. Int. J. Toxicol., 26, 31-77 (2007)

Krogh, K.A., B. Halling-Sorensen, B.B. Mogensen and K.V. Vejrup: Environmental properties and effects of nonionic surfactant adjuvants in pesticides:Areview. Chemosphere, 50, 871-901 (2003).

Kumar, A., S.Li, C.M. Cheng and D. Lee: Recent developments in phase inversion emulsification. Ind. Eng. Chem. Res., 54, 8375-8396 (2015). 
Mostafalou, S. and M. Abdollahi: Pesticides: An update of human exposure and toxicity. Arch. Toxicol., 91, 549-599 (2017).

Mubeen, M., H.M. Arshad, Y. Iftikhar, I. Bilqees, S. Arooj and H.M. Saeed: In-vitro Efficacy of antibiotics against Xanthomonas axonopodis pv. citri through inhabitation zone techniques. Int. J. Agric. Appl. Sci., 7,67-71 (2015).

Mutlu, H. and M.A. Meier: Castor oil as a renewable resource for the chemical industry. Eur. J. Lipid Sci. Technol., 112, 10-30 (2010).

Nangbes, J.G., J.B. Nvau, W.M. Buba and A.N. Zukdimma: Extraction and characterization of castor (Ricinus communis) seed oil. Int. J. Eng. Sci., 2, 105-109 (2013).

Ogunniyi, D.S.: Castor oil: A vital industrial raw material. Bioresour. Technol., 97, 1086-1091 (2006).

Patel, V.R., G.G. Dumancas, L.C.K. Viswanath, R. Maples and B.J.J. Subong: Castor oil: Properties, uses and optimization of processing parameters in commercial production. Lipid Insights, $\mathbf{9}$, 1-12 (2016).

Perazzo, A., V. Preziosi and S. Guido: Phase inversion emulsification: Current understanding and applications. Adv. Colloid Inter. Sci., 222, 581-599 (2015).

Pratap, A.P. and D.N. Bhowmick: Pesticides as microemulsion formulations. J. Disper. Sci. Technol., 29, 1325-1330 (2008).

Roso, A., F. Clemenceau, J. Guilbot and S. Kerverdo: Simulgreen ${ }^{\text {TM }}$ 18-2: A new green based o/w emulsifying structure for concentrated performances. Cosmet. Sci. Technol., pp. 1-5 (2012).

Saini, P., M. Gopal, R. Kumar, R. Gogoi and C. Srivatsava: Bioefficacy evaluation and dissipation pattern of nanoformulation versus commercial formulation of pyridalyl in tomato (Solanum lycopersicum). Environ. Monit. Assess., 187, 1-9 (2015).

Sanchez, R., J.M. Franco, M.A. Delgado, C. Valencia and C. Gallegos: Rheology of oleogels based on sorbitan and glyceryl monostearates and vegetable oils for lubricating applications.
Grasas Aceites, 62, 328-336 (2011).

Savic, S., M. Lukic, I. Jaksic, S. Reichl, S. Tamburic and C. MullerGoymann: An alkyl polyglucoside-mixed emulsifier as stabilizer of emulsion systems: The influence of colloidal structure on emulsions skin hydration potential. J. Coll. Interf. Sci., 358, 182191 (2011)

Salimon, J., D.A.M. Noor, A.T. Nazrizawati, M.M. Firdaus and A. Noraishah: Fatty acid composition and physico-chemical properties of Malaysian castor bean Ricinus communis L. seed oil. Sains Malaysiana, 39, 761-764 (2010).

Sharma, P., A.U. Hqu and R. Singh: Cypermethrin induced reproductive toxicity in male Wistar rats: Protective role of Tribulus terrestris. J. Environ. Biol., 34, 857-862 (2013).

Sivakumar, M., S.Y. Tang and K.W. Tan: Cavitation technology-Agreener processing technique for the generation of pharmaceutical nanoemulsions. Ultrason. Sonochem., 21, 2069-2083 (2014).

Stone, D.: Cannabis, pesticides and conflicting laws: The dilemma for legalized states and implications for public health. Regul. Toxicol. Pharmacol., 69, 284-288 (2014).

Sulek, M.W., M. Ogorzalek, T. Wasilewski and E. Klimaszewska: Alkyl polyglucosides as components of water based lubricants. J. Surfactants Deterg., 16, 369-375 (2013).

Trujillo-Cayado, L.A., A. Natera, M.C. Garcia, J. Munoz and M.C. Alfaro: Rheological properties and physical stability of ecological emulsions stabilized by a surfactant derived from cocoa oil and high pressure homogenization. Grasas Aceites, 66, 1-8 (2015).

Wiacek, A. and E. Chibowski: Zeta potential, effective diameter and multimodal size distribution in oil/water emulsion. Colloids Surf. $A$ : Physicochem. Eng. Asp., 159, 253-261 (1999).

Zhang, H. and S. Wang: Rice versus Xanthomonas oryzae pv. oryzae: A unique pathosystem. Curr. Opin. Plant Biol., 16,188-195(2013). 